\title{
POBLAMIENTO Y ECONOMÍA EN EL BAJO EBRO EN ÉPOCA ROMANA. BASES PARA UN MODELO DE PAISAJE RURAL.
}

\author{
VÍCTOR REVILLA CALVO \\ Dept. Prehistoria, Historia Antigua y Arqueología \\ Universidad de Barcelona
}

\begin{abstract}
El artículo analiza las formas del poblamiento y las estructuras socio-económicas del Bajo Ebro en época romana. Se plantean, en particular, las relaciones entre la distribución del habitat, el paisaje rural, las estructuras de la producción agrícola y de la propiedad. Se analiza igualmente el origen y evolución histórica de estas estructuras, así como su integración en un marco político, social y económico más amplio, constituido por la provincia Tarraconense.

This paper analyses the settlement patterns and the social-economic structures in Bajo Ebro in Roman times. It covers especifically relationships among settlements, rural landscape, structures of agricultural production and landowning. Likewise, the origin and historical evolution of these structures are studied, as well as their role within a broader political, social and economic framework in the Province of Tarraconensis.
\end{abstract}

\section{ECONOMÍA RURAL Y ESTRUCTURAS DE POBLAMIENTO: LA EVIDENCIA ARQUEO- LÓGICA}

\subsection{Planteamientos metodológicos y límites del trabajo.}

El progreso de la investigación arqueológica en los últimos años ha permitido señalar la existencia, en el Bajo Ebro, de un poblamiento rural denso, que ocupa la etapa final de la República y toda la época imperial. Este poblamiento, representado principalmente por la difusión de villae y núcleos o estructuras productivas vinculadas a éstas (prensas, alfares), presenta unas características homogéneas en su implantación, organización interna y cronología. Su distribución y el paisaje rural del que forma parte son el resultado tanto de unas estrategias políticas y socioeconómicas como de las características particulares de la geografía de la zona. Esta situación, unida a la 


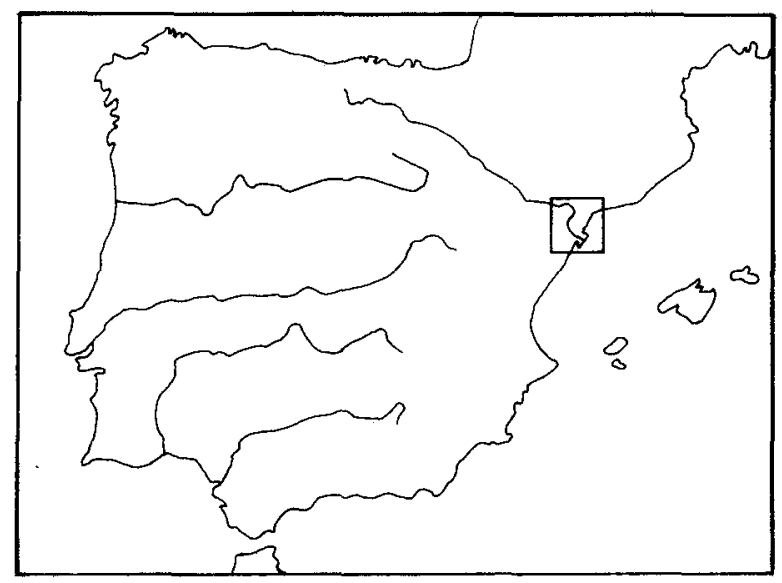

Fig.1.- Situación del valle inferior del Ebro.

precocidad del proceso de romanización, convierten a esta área en una muestra representativa de los modelos de organización del espacio rural que debieron aplicarse en el noreste de Hispania. El interés de esta área como objeto de estudio se ve incrementada, además, por la importancia del valle del Ebro en su conjunto en el proceso de conquista y romanización de la península y, más concretamente, en la organización e integración de la Tarraconense en el sistema provincial romano (N. DUPRE, 1973; ead., 1985a; ead., 1989).

La definición de unos modelos económicos y de poblamiento es fundamental para definir el alcance y características de lo que entendemos por romanización. De hecho, no tenerlos en cuenta supone limitar nuestra comprensión de este fenómeno y orientar la investigación por una vía ya agotada: la enumeración de datos culturales, tomados aisladamente y convertidos en criterio de valoración absoluta en una hipotética escala de «progreso cultural» de las poblaciones indígenas de la península. En esta perspectiva, ciertos elementos (el latín, la onomástica itálica, la asimilación de deidades o la difusión de elementos artísticos) aparecen como puntos de referencia o etapas de este progreso. Este tipo de análisis limita las posibilidades de plantear los factores y el nivel de transformación de las estructuras de una sociedad, pues estudia aisladamente algunos de los elementos en juego, quizá los más superficiales, sin valorar el significado de su adopción. Esto es lo que resulta, por ejemplo, de identificar el grado de romanización con la presencia del latín, o de cultos romanos en una zona. Ni qué decir tiene que un procedimiento semejante niega el papel de las poblaciones autóctonas, convertidas en un elemento pasivo y meramente asimilador.

Simultáneamente, esta orientación del análisis impide situar los mecanismos sociales, económicos o políticos de transmisión o cambio cultural en un marco histórico más amplio en el cual podamos entender, tanto la actuación de Roma como las posibilidades y condicionantes en la respuesta de las sociedades indígenas. Este marco resulta de una situación nueva, creada por la conquista romana y la intervención posterior que se plasma en el sistema provincial: una construcción política, administrativa y fiscal en la que se encuadran forzosamente territorios y comunidades. La creación de esta estructura constituye un primer paso en el proceso de transformación de las sociedades indígenas, puesto que constituye el medio de actuación del estado romano para satisfacer sus necesidades político-estratégicas. En este sentido, es evidente que ciertos factores, dictados por estas necesidades, inciden con fuerza sobre las estructuras socio-económicas y políticas locales. Por ejemplo, las exigencias fiscales y de reclutamiento; pero también la misma superposición de un poder político que se sitúa más allá de los intereses o de las posibilidades de control o resistencia de las comunidades, y que puede imponer a éstas el mantenimiento de un determinado orden social.

Al mismo tiempo, la estructura administrativa y la actuación del estado romano constituyen el marco en el que se inserta otro elemento: las migraciones de itálicos a Hispania. La implantación de amplios grupos humanos, culturalmente diferentes, organizados o no por el estado, tiene su reflejo en la estructuración del territorio provincial sobre nuevas bases. En este contexto debemos incluir, tanto el proceso de urbanización (promoción de comunidades indígenas; creación de núcleos, colonias o municipios, según el modelo itálico) como la configuración de un paisaje rural.

Las posibilidades de establecer unos modelos socio-económicos dependen en buena parte del carácter y estado de la documentación. A este respecto, el conocimiento arqueológico de la zona presenta algunas limitaciones. La lectura de las obras más recientes sobre villae y poblamiento rural en Hispania nos muestra un vacío casi total; tan sólo tres yacimientos aparecen en la síntesis de J.G. Gorges: Alfara, Benifallet y Bitem (J.G. GORGES, 1979, 407, 409, 411). Todos ellos se concentran alrededor de Tortosa. No hay una sola mención al poblamiento detectado en 
otras áreas del curso inferior del Ebro, incluidos yacimientos importantes, repetidamente citados en la bibliografía sobre economía rural en la Tarraconense. Este es el caso del alfar de l'Aumedina (Tivissa), presente en todos los estudios sobre la viticultura en esta zona en los s. I a.C.-I d.C. (vid. infra). Por otro lado, al basarse en la recogida de obras generales y en el vaciado exclusivo de las grandes series periódicas, esta síntesis no va más allá de proporcionar datos escasos, sin entrar en las características de estos núcleos y, más concretamente, en aquellos elementos que podrían definir el modelo o modelos económicos en que se enmarcan.

Problemas similares ofrecen los escasos intentos de síntesis regional realizados hasta el momento. En todos estos casos es evidente un progreso en el inventario de yacimientos, resultado del mejor conocimiento de la realidad local: intervenciones programadas o de urgencia, actividades de aficionados, referencias a bibliografía de escasa difusión'. Sin embargo, esta acumulación de información es el resultado de esfuerzos discontinuos y no siempre realizados con criterios y en condiciones científicas idóneas, lo que perjudica su valor. A ello hay que añadir la falta de excavación, siquiera parcial, de la inmensa mayoría de yacimientos. El resultado es un catálogo de lugares de los que es difícil precisar entidad y cronología.

Forzosamente, ello deja sin responder muchas cuestiones. Entre éstas, la más importante es la posibilidad de establecer una tipología de núcleos: ¿se trata siempre de villae y es éste, en consecuencia, el modelo organizador del espacio rural? A la vez, esta problemática debe enmarcarse en un contexto más general: ¿cuál es la cronología de este poblamiento rural y en qué marco económico se incluye? ¿cuál o cuáles son las formas de organización de la producción y cómo podemos relacionarlas con unas formas de propiedad y unos sistemas de gestión de la explotación agrícola?² Se trata de cuestiones que afectan directamete a las posibilidades de interpretación y definición de los núcleos rurales, su situación en el espacio y sus relaciones entre sí; por ejemplo en relación con una jerar-

'Entre la bibliografía referente a la zona pueden destacarse: $D$. CABRE, 1974, M. GENERA, 1977 ead., 1982, M. GENERA; M.J. JASSANS, 1978. La información actualmente disponible sobre la zona se ha visto aumentada por los inventarios del patrimonio comarcal realizados por el Servei d'Arqueologia de la Generalitat; de estos se ha publicado uno hasta el momento: Inventari del Patrimoni Arqueologic de Catalunya. Montsià (Barcelona, 1988). quía del asentamiento. No podemos interpretar cada yacimiento como un elemento aislado. Sus características e implantación sólo se comprenden en un marco más amplio, el paisaje rural de la zona entendido como el resultado de unas estrategias económicas y sociales de una sociedad culturalmente compleja.

Una segunda dificultad para la investigación resulta de la propia naturaleza del método de trabajo y de la información obtenida. La arqueología difícilmente puede responder a ciertos problemas que plantea el conocimiento del medio rural en época romana: extracción étnica y social de los grupos humanos protagonistas (por ejemplo, el papel de la inmigración itálica); los sistemas de propiedad y de gestión que están detrás de los procesos productivos (tamaño y formas de la propiedad, formas del trabajo); el estatuto jurídico y social de la población del campo. Un problema especial, en el mundo romano, es el de la relación entre la ciudad y el medio rural, fundamentalmente para entender la configuración de un paisaje romanizado y las formas particulares que asume el poblamiento ( $\mathrm{Ph}$. LEVEAU, 1983, 924ss.). A la vez, esta relación se expresa en una diversidad de formas (económicas, sociales y jurídico-políticas), la mayor parte de las cuales reflejan la dependencia del campo frente a la ciudad: fiscalidad, extracción de rentas privadas, estatutos jurídicos de la población rural, existencia de una clase propietaria absentista, formas de gestión de la explotación. Es necesario contar, en todos estos casos, con la ayuda de fuentes históricas para enmarcar la evolución de esta zona en un proceso general de romanización, entendida como un profundo fenómeno de transformación socio-económica. La epigrafía, en esta perspectiva, constituye un complemento indispensable para evidenciar ciertos fenómenos: onomástica, extracción social, o la misma relación territorio-ciudad a través de la dispersión de los nombres (M. MAYER, I. RODA, 1985a). Es evidente que es necesaria una aproximación múltiple, en instrumentos y métodos, si se pretende la comprensión global de un fenómeno socio-económico (el poblamiento romano en el Bajo Ebro) igualmente complejo.

2Para un ejemplo de los problemas planteados por los escasos datos históricos y arqueológicos, vid. N. DUPRE, 1990; este trabajo, centrado en el estudio de la viticultura y comercio del vino en el valle del Ebro, evidencia el escaso conocimiento actual de las formas de la economía agrícola de la zona: estructuras materiales de la producción, sistemas de gestión, propiedad. 


\section{2.- La distribución del poblamiento rural.}

En el área ocupada por las comarcas del sur de Tarragona (Montsià, Baix Ebre y Ribera d'Ebre) se conocen actualmente, más de 50 yacimientos de época romana (fig. 2). El desigual grado de conservación, excavación y estudio impide, en muchos casos, conocer la cronología y naturaleza de estos núcleos. Por otro lado, la falta de prospecciones sistemáticas del territorio no permite precisar si nos hallamos ante una muestra representativa de los patrones de asentamiento, ya que la información recogida es el resultado de esfuerzos discontinuos y concentrados en ciertos lugares por su fácil acceso o por planteamientos a priori insuficientemente contratados. Todo ello relativiza el valor de nuestras conclusiones. Con todo, el número y distribución de los lugares, junto con el conocimiento detallado de algunos de ellos permite avanzar algunas de las características del poblamiento.

La implantación de los asentamientos muestra la importancia fundamental del Ebro y de sus afluentes. Esta red hidrográfica actúa como verdadero eje vertebrador del territorio, asegurando su comunicación y explotación económica (F. CARRERAS CANDI, 1940; A. BELTRAN, 1961; N. DUPRE, 1973, 138 ss.). Esta razón explica que la gran mayoría de los yacimientos conocidos aparezcan en la proximidad del río. En todos los casos, se escoge una localización sobre tierras no inundables, en las laderas o la cima de pequeñas colinas situadas junto al río; generalmente, se trata de elevaciones situadas entre el Ebro y algún pequeño afluente o barranco. Es, por lo tanto, una posición que combina el dominio visual del área circundante, la facilidad de comunicación y el drenaje natural. Parece lógico pensar que esta implantación responde al deseo de explotar los terrenos más cercanos al Ebro, especialmente las zonas bajas, fácilmente irrigables, y formadas por depósitos de aluvión fértiles. Aquí encontramos asentamientos de cierta importancia a juzgar por la entidad de los restos arquitectónicos e infraestructuras productivas. Este es el caso de algunos núcleos identificables como villae: Les Sebiques (Vinebre), Barrugat (Bitem/Tortosa), Casa Blanca (Jesús-Tortosa), la Carrova (Amposta) (M. GENERA, 1982).

Pero también encontramos, aquí, pequeños núcleos, muy pobres en material y sin restos constructivos, que se sitúan en la proximidad de villae. La mayoría de los núcleos rurales conocidos, con independencia de su entidad, se concentran en la zona Ascó-Vinebre, en la Depresión de Mora y en el territorio que se extiende desde Tortosa hasta la costa. Las tres áreas constituyen las únicas zonas amplias y de relieve suave cruzadas por el Ebro en su curso inferior. Las dos primeras presentan, además, la particularidad de quedar delimitadas por estribaciones montañosas que las aíslan y convierten al río en su vía de comunicación principal.

Es en estas mismas zonas donde se sitúan los escasos yacimientos de interior conocidos hasta el momento, incluidos alfares como el de L'Aumedina. Pero su emplazamiento también debe verse en relación con las posibilidades de acceso al Ebro, puesto que todos se sitúan junto a sus principales afluentes o en torrentes. En este tipo de distribución hay que distinguir, en primer lugar, los asentamientos en las terrazas situadas entre las cotas de 100 y 300 metros, en zonas amplias y de relieve suave, organizados y definidos topográficamente por la red hidrográfica. Aquí encontramos algunos establecimientos importantes: L'Aumedina (Tivissa), Els Plans (Mora la Nova), Les Sebiques (Vinebre), la Font de n'Horta (La Torre de l'Español), cuya implantación hay que ver en función de las posibilidades agrícolas de la zona. Con excepción de L'Aumedina, no podemos establecer la entidad de estos núcleos, pero algunos han proporcionado restos arquitectónicos importantes, como la Font de n'Horta (M. GENERA, 1982,103 s.). Igualmente, conocemos núcleos de entidad muy reducida con una posición menos favorable: por encima de los 400 metros, en zonas de relieve accidentado y comunicación difícil. Estos asentamientos reproducen las características del habitat ibérico detectado en zonas del interior como la Terra Alta (E. PUCH, 1986-87). Por su situación, tamaño, modestia de los restos y limitadas posibilidades económicas hay que pensar en pequeños núcleos agrícolas que dependerían de otros mayores.

Los establecimientos identificados como villae no aparecen únicamente en zonas de planicie. La misma implantación, ya señalada, sobre pequeñas colinas situadas entre el Ebro y un barranco, se encuentra en áreas de relieve muy accidentado: zona del pantano de Riba-Roja, Pas de l'Ase y Pas de Barrufemes. Aquí el Ebro discurre encajonado entre estribaciones que pueden alcanzar los $200 \mathrm{~m}$. de altura casi en su misma orilla. Los únicos terrenos 


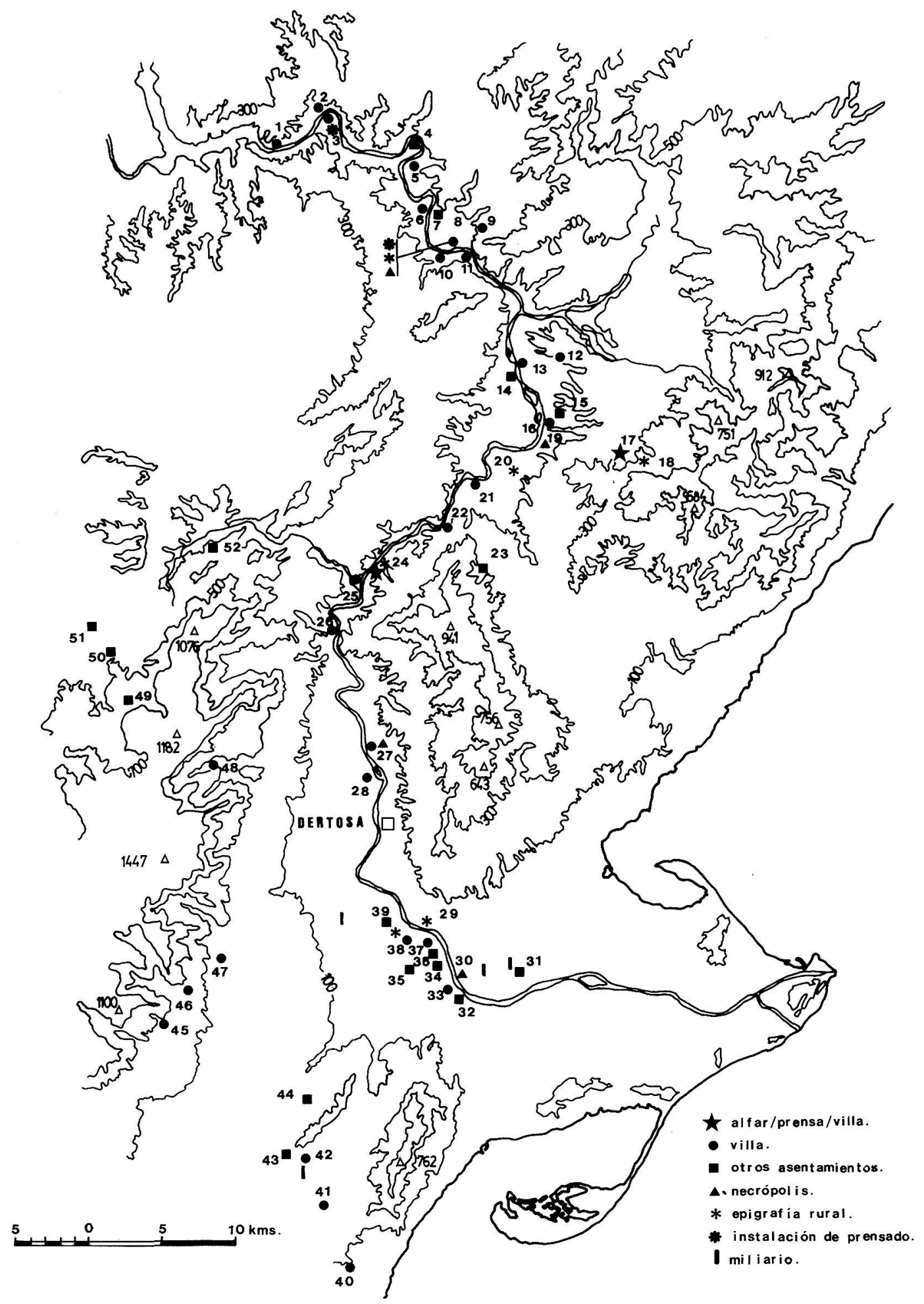

Fig. 2.- El poblamiento romano en el curso inferior del Ebro.

1. Senals; 2. Vall de Porcs; 3. Pradell; 4. Castell de Flix; 5. Castellons (Flix); 6. Els Castellons (Ascó); 7. Racó de la Rata Penada; 8. Les Sebiques, la Fontjoana; 9. La Font de n'Horta; 10. Forn Teuler; 11. Asclines; 12. Els Plans; 13. Les Cases Barates; 14. El Calvari; 15. Barranc Fondo; 16. El Molló; 17. L'Aumedina; 18. Tivissa; 19. Mas de Tramontà; 20. Ginestar; 21. Les Pedres; 22. Barranc de Rasquera; 23. Corriol de Corb; 24. Mas del Catxorro; 25. Ligallo de Lixem; 26 Mas de Xalamera; 27. Barrugat; 28. Casa Blanca; 29. Camp Redó; 30. Mas de la Palma; 31 . Ermita de l'Aldea; 32. Amposta; 33. Plà d'Empuries; 34. Mas de Hierro; 35. Mas de Sant Pau. 36. Molló de la Torre; 37. La Carrova; 38. Mianes; 39. Mianes II; 40. Cementeri d'Alcanar; 41. La Torreta; 42. Mas de la Torre; 43. Cova de les Bruixes; 44. Villalarga; 45. El Carrascal; 46. Castells; 47. Vilar de Sta. Maria/Fabarium; 48. Alfara de Carles; 49. Penya Gall; 50. Mas de Manresa; 51. El Collet; 52. Ermita de Sant Josep. 
amplios y de relieve suave son los pequeños depósitos de aluvión formados en los meandos del río y junto a estas elevaciones. Los mismos valles de afluentes y barrancos son estrechos y escarpados. Sin embargo, buen número de yacimientos, algunos de ellos de cierta entidad, aparecen en estos lugares, dominando franjas de terreno reducidas y, a priori, poco aptas para un cultivo intensivo y a gran escala: Senals (Riba-Roja d'Ebre), Forn Teuler, Asclines (ambos en Ascó), Barranc de Raquera (Miravent), Mas del Catxorro (Benifallet). Sin duda, también en este caso la red hidrográfica formada por el Ebro y sus afluentes juega un papel determinante. La relación con esta red asegura a estos núcleos la comunicación con todo el valle y de éste con el exterior en sentido longitudinal, muy difícil por vía terrestre (J.G. MOROTE BARBERA, 1979; N. DUPRE, 1983; F. PALLI, 1985).

A la vez, es probable que la situación junto a los afluentes responda al deseo de aprovechar los recursos ofrecidos por el interior $\mathrm{y}$, en primer lugar, por las masas forestales situadas en las proximidades del Ebro (N. DUPRE, 1985b). Esto podría constituir un indicio de una explotación económica diversificada de la región, no basada exclusivamente en la agricultura, y nos introduce en una problemática más compleja: las formas en que estas áreas se han integrado en unos sistemas económicos que incluyen la comercialización de recursos naturales. Cabe la posibilidad de un habitat y unas prácticas económicas marginales, en ciertas áreas del curso inferior del Ebro, como resultado de su evolución histórica. Pero también es posible que muchos de estos asentamientos se integren en un sistema más amplio, como elemento complementario de una economía de villa.

\subsection{Arquitectura rural e infraestructura de la pro- ducción.}

\subsubsection{Instalaciones productivas y actividad economica.}

Las escasas excavaciones realizadas hasta el momento impiden definir las características arquitectónicas, infraestructuras y organización interna de los núcleos rurales. Las posibilidades de establecer una tipología del habitat incluyendo estos factores se limitan a algunos yacimientos bien conocidos. Entre estos, los alfares dedicados a la fabricación de ánforas, siempre vinculados a villae, ocupan un lugar especial por sus posibilidades de definir unidades y modelos de explotación del territorio.

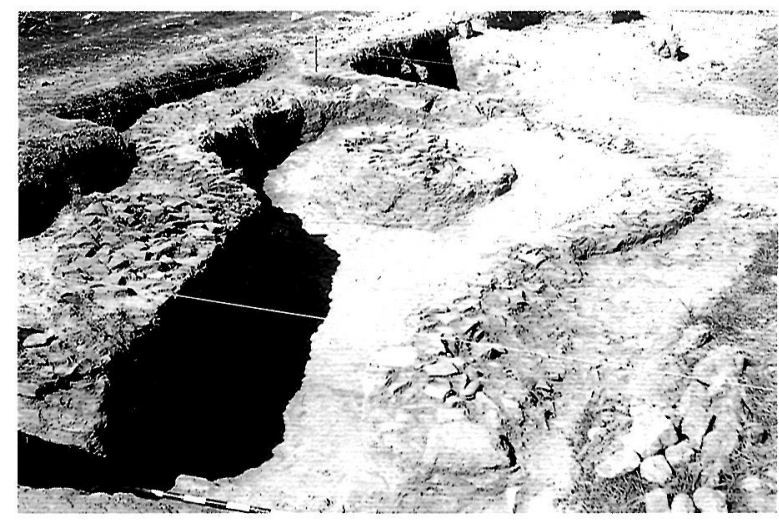

Fig. 3.- L'Aumedina (Tivissa): horno descubierto en la excavación de 1986.

Sin lugar a dudas, el más conocido entre estos alfares es el de L'Aumedina (A. TCHERNIA, 1979; J. M. ${ }^{a}$ NOLLA, J. PADRO, E. SANMARTI, 1980; V. REVILLA, 1993). Las sucesivas intervenciones realizadas en este yacimiento han permitido descubrir un núcleo formado por una instalación de prensado y depósitos de almacenaje, así como varios hornos dedicados a la fabricación de ánforas, dolia, cerámica común y material constructivo (figs. 3-4). Con estos elementos se abastecían las necesidades de instrumenta vinculadas a la vida cotidiana y a la producción agrícola del lugar y de villae próximas. El área de expansión de la producción vinaria envasada en L'Aumedina cubre gran parte de las provincias occidentales del Imperio (limes germánico, Galia, Italia), con una cronología de época augústea (J. MIRO, 1988, 229 s.; V. REVILLA, 1993).

De características similares a L'Aumedina es la villa del Mas del Catxorro, en Benifallet (A. Fig. BALIL, E. RIPOLL, 1952; P. IZQUIERDO, 1993). En este lugar, las intervenciones realizadas entre 1987 y 1989 han permitido descubrir un establecimiento importante situado en una elevación junto al Ebro. Aunque los trabajos agrícolas han supuesto la destrucción de una parte considerable del yacimiento, se conservan varias habitaciones, canalizaciones y un depósito en opus signinum. La importancia del habitat se refleja también en la existencia de una necrópolis. El conjunto contaba, además, con un importante sector productivo que incluía una instalación de prensado (se han recuperado tres contrapesos de prensa) y un vertedero con material anfórico que incluye rechazos de horno (fig. 5). Estos elementos hacen pensar en la 


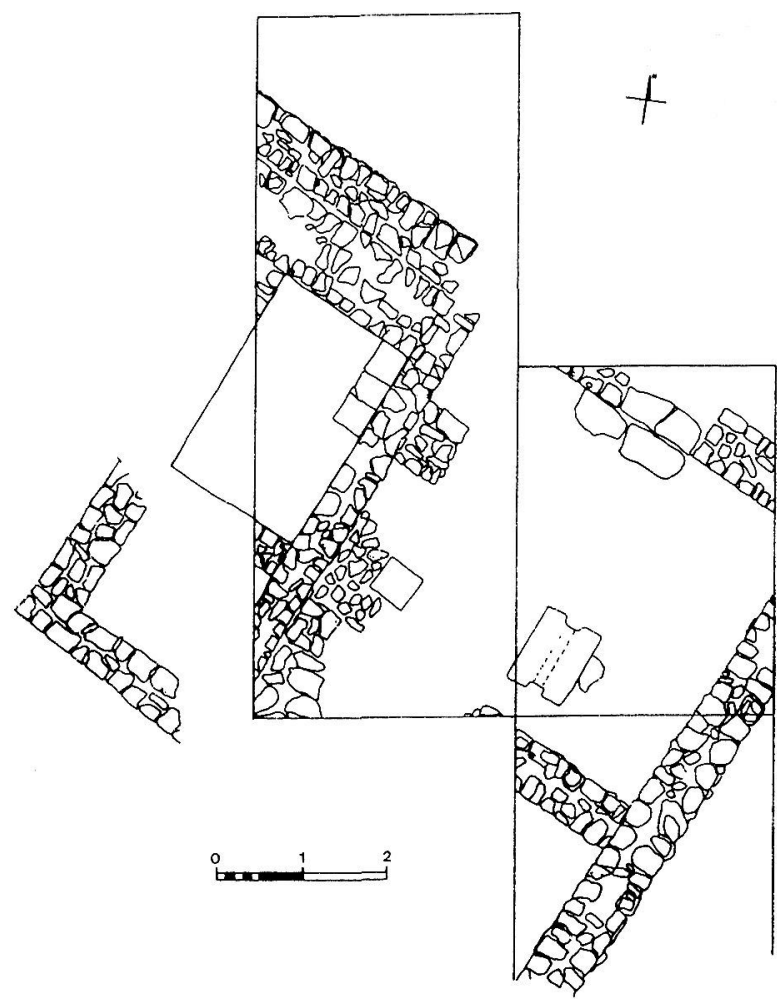

Fig. 4.- L'Aumedina (Tivissa): planta de la instalación de prensado (según R. Pallarès, F. Gracia, G. Munilla; 1987).

existencia de un alfar que, a juzgar por el material, responde a características de producción similares a las de L'Aumedina: producción anfórica diversificada, cerámica común, material constructivo. Los materiales producidos, así como la cronología de la difusión de sus marcas, sitúan el período de actividad del alfar en época de Augusto. Esta identidad de producciones y cronología con L'Aumedina es paralela a una distribución que afecta prácticamente a los mismos mercados (J. MIRO, 1988, 219; J. REMESAL, V. REVILLA, 1991).

Estas características incluyen a ambos núcleos en un mismo fenómeno de producción agrícola, capaz de producir y comercializar unos excedentes y que comporta unas inversiones tecnológicas similares: prensas, obviamente destinadas a cubrir unas necesidades excedentarias y no domésticas; medios relacionados con el almacenamiento y exportación del producto; una producción cerámica diversificada, destinada al abastecimiento prioritario de la explotación ${ }^{3}$. Esta producción excedentaria (con su organización e inversiones) supone una vinculación a estructuras comerciales,

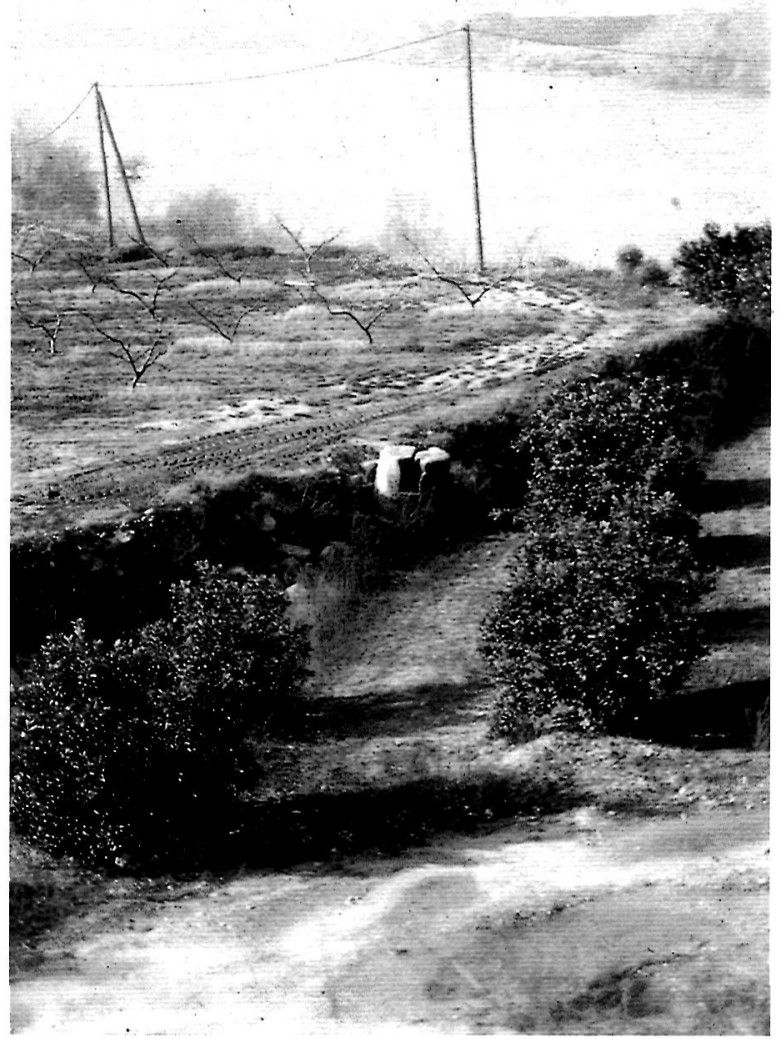

Fig. 5.- Mas del Cachorro (Benifallet): vista general del emplazamiento; en primer término, contrapeso de prensa hallado in situ.

pero también a formas de circulación no económicas (fiscalidad, requisiciones, etc.). Unas y otras explican la capacidad de exportación a mercados distantes, algunas formas de circulación concretas (por ejemplo, las asociaciones constantes entre alfares de una misma área o entre áreas diversas en ciertos lugares) y la naturaleza misma de los mercados y grupos consumidores interesados (J. REMESAL, V. REVILLA, 1991).

Es más difícil de establecer, en el caso del bajo Ebro, la relación entre unas estrategias económicas, que incluyen inversiones, transformaciones tecnológicas y el incremento de la producción, y una

3 Para las instalaciones de prensado y almacenaje: K.D. WHITE, 1970 425, id., 1975107 ss. y 225 ss., J.J. ROSSITER, 1981; J.P. BRUN, 1986,122; un intento de relacionar tecnología y procesos productivos en una perspectiva etnográfica en: M.C. AMOURETTI et al., 1984. 
intervención planificada sobre el paisaje rural. En concreto, ¿existen transformaciones (drenajes, obras de infraestructura, viabilidad) asociadas a un modelo basado en la creación y comercialización de una producción excedentaria y especializada como es el vino? ¿Cómo se relacionaría este fenómeno con una organización del territorio con fines administrativos y fiscales? $?^{4}$ La peculiar geografía del Ebro impone algunos límites a un estudio de este tipo. Por otro lado, sólo grandes intervenciones de transformación y planificación agrícola generan la documentación histórica y arqueológica que permite reconstruir un proceso de estas características; pensamos, concretamente, en una política oficial de colonización. De hecho, es más fácil identificar unas infraestructuras y relacionarlas con el habitat y con unas prácticas económicas, que establecer la relación concreta entre la evolución de los establecimientos rurales y las modificaciones puntuales que puede haber sufrido el paisaje (G. TOSI, 1989). Sin embargo, estas modificaciones debieron producirse en esta y otras áreas de la Tarraconense litoral relacionadas con el desarrollo de una agricultura excedentaria y el poblamiento en villae.

No se han identificado, hasta el momento, otros alfares en el curso inferior del Ebro. Sin embargo, no es probable que el desarrollo de la actividad alfarera se limitara a los dos lugares conocidos y que el fenómeno de producción vinaria y exportación ejemplificado por ambos talleres constituya un hecho aislado. Que esta producción excedentaria existe lo prueban otras instalaciones de prensado en diversos núcleos. Muy recientemente, se ha identificado, en la Fontjoana (Vinebre), un gran contrapeso, formando parte de una instalación situada junto al río y muy cercana a los restos de una villa de cierta importancia: Les Sebiques (M. GENERA, 1982, 96; ead., 1990a; ead., 1990b). También se ha descubierto otro contrapeso en Pradell (Riba-Roja d'Ebre). La falta de exca-

${ }^{4} \mathrm{El}$ problema de la relación entre viticultura, habitat y organización del espacio rural se ha planteado, también, en otras zonas del imperio romano en las que se conoce una producción excedentaria y una fuerte comercialización del vino: M. CLAVELLEVEQUE, F. LAUBENHEIMER, 1984; M. CLAVEL-LEVEQUE, 1984; estas cuestiones apenas se han abordado en el estudio de la viticultura en el NE de la Tarraconense, lo que refleja la falta de un análisis cuidadoso de las estructuras de la producción y la propiedad rural en la Cataluña romana (V. REVILLA, 1993).

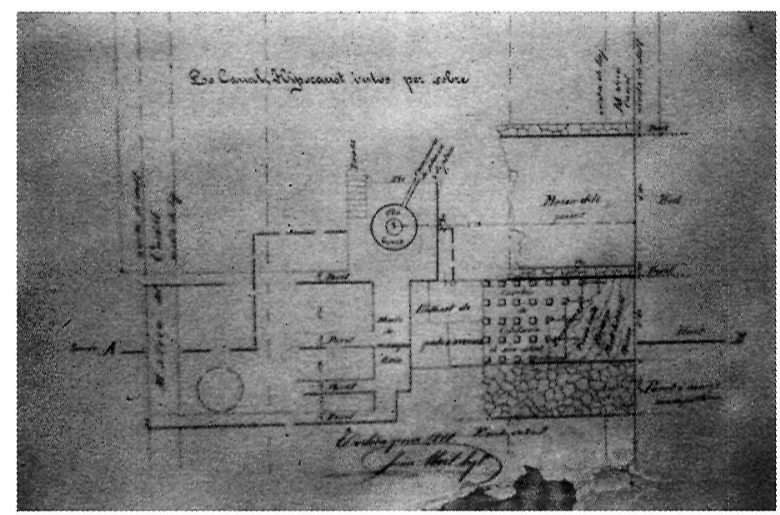

Fig. 6.- Barrugat (Bitem, Tortosa): planta general del sector descubierto en 1910 (según J. Abril i Guanyabens, 1931).

vación impide precisar el contexto y cronología del hallazgo, pero su situación cercana al río, la extensión del lugar y la aparición de otras estructuras hacen pensar en una villa (M. GENERA, 1982, 58; D. CABRE, 1974). A estos hallazgos hay que añadir los restos de dolia para almacenaje aparecidos in situ en la villa de Berrugat, en Bitem, Tortosa (J. ABRIL I GUANYABENS, 1931; E. BAYERRI, 1948, 662; M. GENERA, 1983-84; ead., 1990c).

\subsubsection{La arquitectura}

La distribución y características arquitectónicas de estos núcleos son tan poco conocidas como sus instalaciones productivas. Las recientes excavaciones realizadas en Barrugat, en el margen izquierdo del Ebro, han permitido descubrir habitaciones dotadas de hipocaustos y diversos fragmentos de mosaicos, restos de la decoración de un sector que pueden interpretarse como las termas de la villa (fig 6-7). Estos datos completan el plano realizado, en 1910, a raíz de la destrucción parcial del lugar, que muestra un establecimiento importante y una cuidadosa planificación arquitectónica.

Muy cerca de Barrugat, en la orilla opuesta, se sitúa la villa de Casa Blanca (Jesús-Tortosa). Las intervenciones realizadas, entre 1986 y 1987, han permitido descubrir un sector importante del establecimiento (fig. 8) (E. BAYERRI, 1948, 293; M. GENERA, J.V. M ${ }^{a}$ ALBELOA, 1987, 87 s.; J.V. M ${ }^{a}$ ALBELOA, 1990). Este se ordena alrededor de un patio rectangular de $10 \times 17 \mathrm{~m}$., limitado lateralmente por grupos de habitaciones y por un gran muro frontal reforzado por contrafuertes. El conjunto se dispone en la parte inferior de la ladera de una colina, cara al 


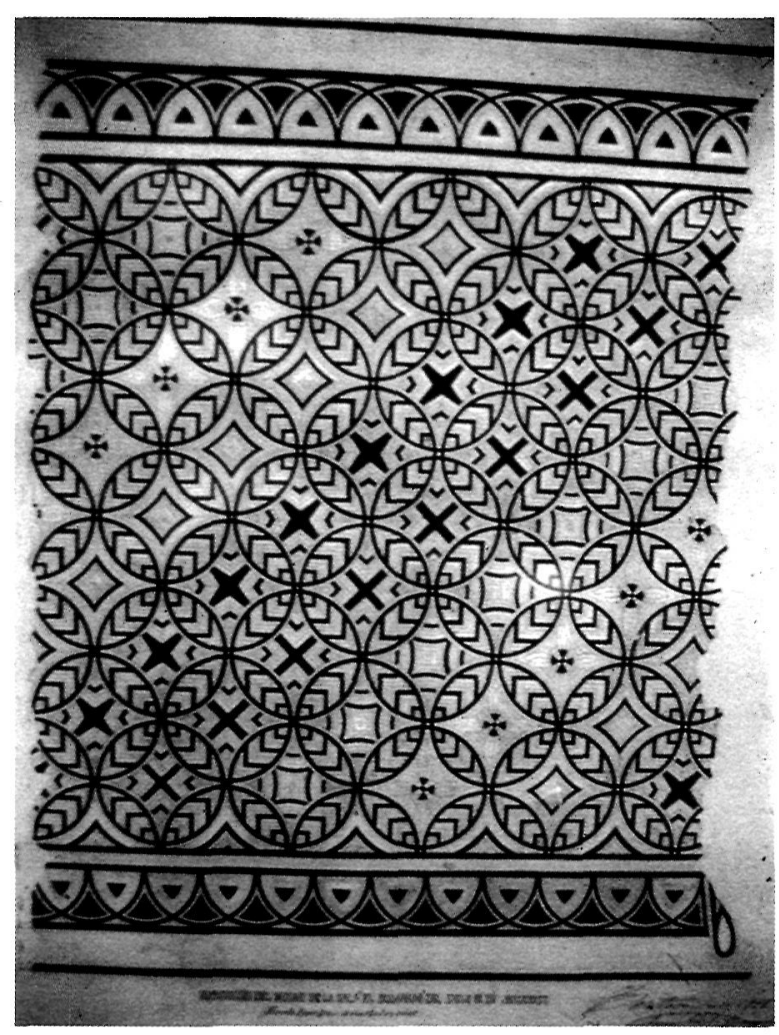

Fig. 7.- Barrugat (Bitem, Tortosa): mosaico descubierto en 1910 (según J. Abril i Guanyabens, 1931).

Ebro. Las estructuras se prolongan en la zona superior, seguramente en forma de diversos cuerpos escalonados, ya que se conservan muros, grandes conducciones de agua, depósitos en opus signinum y un pequeño horno. Otros elementos señalan la importancia de este lugar, como la extensión de los restos (el área ocupada por las estructuras visibles es de unos $6.000 \mathrm{m.}^{2}$ ) y, especialmente, la planificación arquitectónica del conjunto. Su disposición en cuerpos, dispuestos escalonadamente en la ladera y orientados al río muestra un concepto escenográfico y una organización del espacio perfectamente planificado, tras la cual se hallan unos modelos sociales, ideológicos y estéticos característicos de la arquitectura de villae y que acompañan su implantación en Italia y las provincias a finales de la República y en el Alto Imperio (X. LAFON, 1981a; J.P. VALLAT, 1983). La misma disposición, favorecida por la implantación junto al Ebro, aparece en otras villae: la Carrova, en Amposta (F. ESTEVE GALVEZ, 1954-55); Les Sebiques, en Vinebre (M. GENERA, 1982, 96); Les Pedres, en Miravet (M. GENERA, M.J.

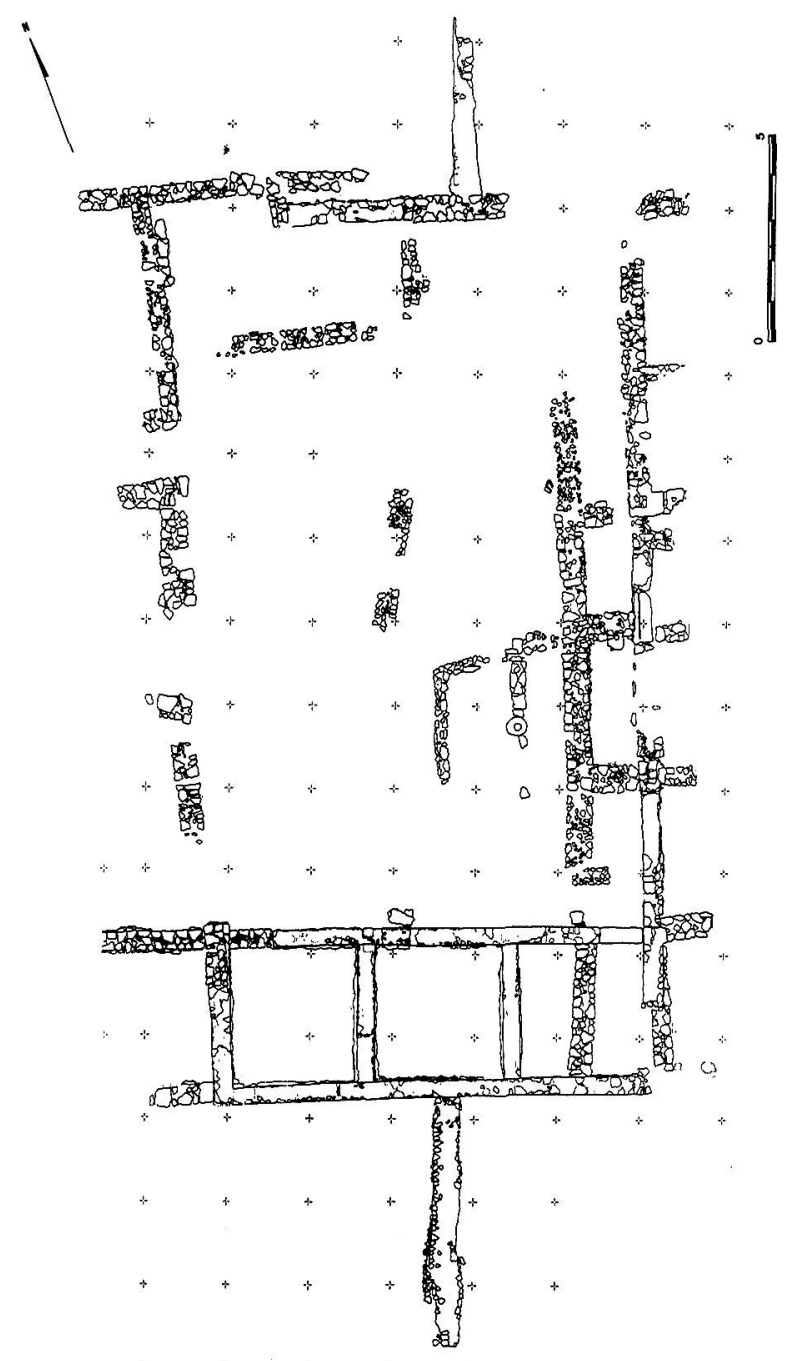

Fig. 8.- Casa Blanca (Jesús, Tortosa): planta general del sector de la villa excavado en 1987.

JASSANS, 1978, 295); o en la ya citada del Mas del Catxorro, que conserva importantes construcciones en la orilla misma del río. Es evidente que, tanto como la comunicación, en todos estos casos se valoró la disposición del conjunto por su visibilidad, buscando una fuerte implantación sobre el paisaje que refleja el carácter de la villa cómo centro de una explotación y residencia (J.P. VALLAT, 1983, 254).

Los modelos mencionados comportan igualmente el desarrollo de unos programas técnicos aplicados a usos residenciales, abastecimiento de agua o calefacción, por ejemplo, que encuentran expresión en el desarrollo de infraestructuras complejas en las villae. 
Las referencias en los agrónomos latinos son numerosas a este respecto. Ello es debido a la variedad de usos del agua domésticos y productivos, en una explotación rural ${ }^{\text {s. }}$ El mismo fenómeno encontramos en el curso inferior del Ebro: los depósitos y las grandes conducciones de agua de Casa Blanca, las habitaciones con hipocaustos de que estaba dotada Barrugat, interpretados como sector termal, etc. Todo ello se complementa con unos programas ornamentales: terracotas arquitectónicas (Casa Blanca), mosaicos (Barrugat). Se trata de ejemplos escasos, pero reveladores de la difusión de unas determinadas formas de residencia y, en consecuencia, de los programas técnicos que constituyen su aplicación práctica.

Por lo demás, es evidente un esfuerzo planificador en estas villae, que se traduce en una distribución ordenada del espacio y de las funciones. En Casa Blanca, la zona superior de la colina, donde se concentran los restos de mayor entidad, correspondería probablemente al área residencial. En la zona inferior, alrededor del patio y organizadas en forma geométrica y unitaria se distribuyen los espacios destinados, muy posiblemente, a actividades productivas. Ello nos conduce, nuevamente a un modelo determinado de organización del núcleo rural, que encuentra su reflejo en las normas de los agrónomos sobre la organización del conjunto, a la vez como residencia (lo que supone la adecuación a vivienda de un propietario) y centro productivo ${ }^{6}$.

Esta organización unitaria, con la distribución ordenada y regular de espacios geométricos similares, supone, también, una determinada práctica arquitectónica, basada en el uso de unas técnicas y materiales precisos: mortero y encofrado. En este hecho reside la notable homogeneidad constructiva que muestran muchos lugares: Casa Blanca, la Carrova, les Pedres, barranc de Rasquera, les Sebiques, la Font de n'Hort

${ }^{5} \mathrm{Cf}$. Ias distintas prescripciones acerca del agua en los agrónomos: proximidad y abundancia (VARRO, RR. 1.11.2; COLUM., $R R$. 1.5.1-4), aptitud para el consumo (COLUM., RR. 1.5.3.; PLIN $H N$. XIX 60; PALLAD. 1.17.4), infraestructuras de captación, almacenaje y distribución (COLUM., RR. 1.5.2; VARRO, $R R$. $1.11 .2,1.13 .1$ la presencia de conjuntos termales en las villas, COLUM. 1.6.2, 1.6.19- PLIN., HN. XVIII.7, para estos aspectos, A. GRENIER, 1960, 235 ss.

' CATO, De Agr., 4; VARRO, RR 1.11-13; COLUM., RR. 1.4.8-1.6; VITR, VI.6; para la relación entre status social y programas decorativos y arquitectónicos: X. LAFON 1981b; VALLAT, $1983,251 \mathrm{ss}$

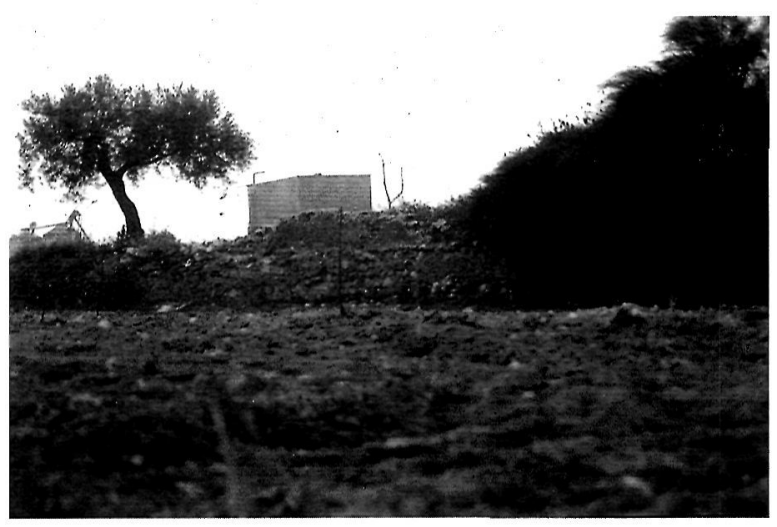

Fig. 9.- Les Sebiques (Vinebre): zona superior de la villa, estructuras actualmente visibles.

(figs. 9-10). En última instancia, esta arquitectura es el resultado combinado de unos modelos ideológicos, que definen el ideal de vida, comportamiento y status de un determinado grupo social, y de las relaciones socio-económicas que rigen el medio rural.

\section{LA DEFINICIÓN DE UN MODELO DE POBLAMIENTO: BASES ECONÓMICAS Y SOCIALES}

\subsection{Las estructuras de la producción agrícola.}

La importancia de yacimientos como Casa Blanca, Barrugat o Mas del Catxorro, obliga a plantear la naturaleza exacta de los asentamientos y sus relaciones mutuas. De forma paralela, es necesario definir la capacidad transformadora del poblamiento sobre el paisaje rural, entendiendo este poblamiento como resultado de unas determinadas estructuras socio-económicas. ¿Podemos definir las estructuras en las que se basa la organización del poblamiento? Responder a esta pregunta supone plantear una serie de cuestiones fundamentales: propiedad de la tierra, sistemas de gestión y trabajo, estrategias ecónomicas.

Todos estos factores se integran en un mismo sistema económico. A la vez, no podemos disociarlos de un marco histórico y socio-político más general constituido por la evolución de la provincia Tarraconense.

En este sistema, la relación de la producción agrícola con unos circuitos de distribución y mercados amplios aparece como un elemento central. Esta vinculación está en la base de la creación de un excedente y de una tendencia, aunque nunca total, hacia la especia- 


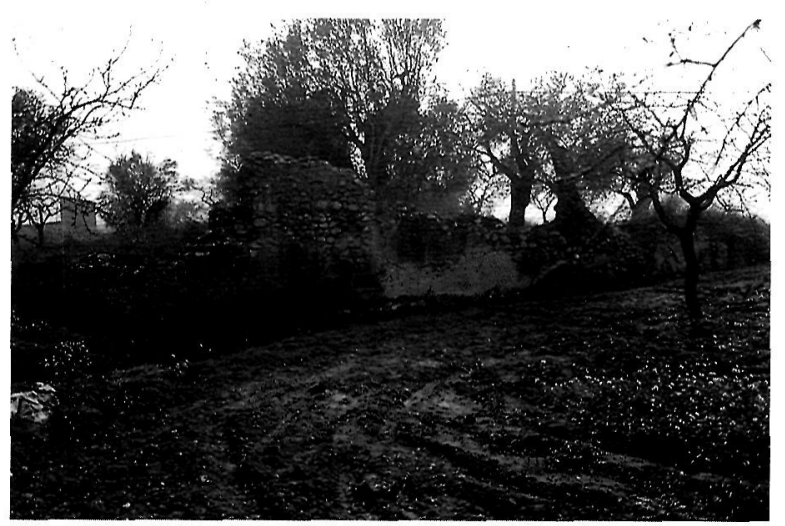

Fig. 10.- La Font de n'Horta (La Torre de l'Espanyol): restos arquitectónicos de la villa.

lización en los cultivos. A la vez, unos y otros factores imponen unas formas de gestión y de trabajo (orientadas a conseguir el máximo rendimiento), un volumen de inversión determinado, la creación de infraestructuras y unas formas de relación con la comercialización del producto (M. CORBIER, 1981; L. CAPOGROSSI COLOGNESI, 1981). En este contexto, la villa, entendida como forma de poblamiento y explotación económica (unida a unos sistemas de propiedad y gestión y a unas relaciones sociales), es uno de los modelos posibles. Por las formas de implantación en Italia y en las provincias y por sus connotaciones como modelo social y cultural, a la vez que económico, la villa ha constituido un objeto de estudio privilegiado, aunque no es el único modo de organización y explotación del espacio rural en el mundo romano (Ph. LEVEAU, 1983, 928 ss.). ¿Cómo se refleja todo esto en el paisaje humano del Bajo Ebro?

La evidencia arqueológica analizada muestra que la villa constituye el modelo que define la ocupación y explotación de este territorio. En concreto, parece que deben considerarse como tales la mayoría de los núcleos situados junto al Ebro, o en las terrazas fluviales que se escalonan entre las cotas de 100 a 300 $400 \mathrm{~m}$. Una serie de factores avalan esta atribución: la entidad arquitectónica de los restos; su disposición en el paisaje, controlando amplias zonas (y buscando un fuerte efecto visual o escenográfico); su planificación unitaria y distribución funcional. Todos estos elementos definen a estos yacimientos como residencias y centros de una explotación (Ph. LEVEAU, 1983, 922; J.G. GORGES, 1979,11 ss.). La misma concentración o dependencia de las infraestructuras de la producción con respecto a estos lugares muestra la posición central de la villa en el proceso económico.

Esta vinculación villa-actividad económica puede tomar diversas formas sobre el territorio. Una de ellas es la unión de todas las actividades en un mismo lugar y de acuerdo con una distribución funcional cuidadosa. Este es el caso de L'Aumedina o del Mas del Catxorro, donde instalaciones de prensado, depósitos y alfares se disponen sobre una misma área. Pero también podemos encontrar una distribución descentralizada sobre un espacio más amplio, generalmente separando la zona de habitat y ciertas actividades productivas. Esto supone una distribución jerarquizada en la que la villa actúa como centro organizador y en la que diversos lugares de la explotación se especializan en procesos o fases del ciclo agrícola. Un ejemplo de ello podemos tenerlo en les Sebiques-la Fontjoana. Aquí, el habitat principal se localiza sobre una elevación que controla visualmente una amplia zona, mientras que la instalación de prensado se sitúa a unos 500 m., en un punto próximo al río (¿en función de la exportación de la producción agrícola?). También puede pensarse en una distribución jerarquizada para una serie de pequeños asentamientos situados junto al Ebro, o en sus proximidades, y conectados a la red hidrográfica: Mas de Sant Pau, en Masdenverge; Mianes II, en Tortosa. Esta disposición muestra unas necesidades de comunicación exterior. Al mismo tiempo, su emplazamiento, entidad modesta y proximidad a verdaderas villae hace pensar en núcleos (habitados de forma permanente o estacional) cuya razón de ser económica depende de su vinculación a una explotación mayor ${ }^{7}$ Las posibilidades que ofrecen estos núcleos son muy diversas; desde formar parte del ciclo estacional de trabajos agrícolas,

${ }^{7}$ Estos lugares coinciden en la ausencia de restos constructivos (con excepción de algunas tegulae) y la escasez de materiales cerámicos, dispersos en áreas reducidas (no superiores a $400 \mathrm{~m}^{2}$ ). Es muy probable que cierto número de núcleos con materiales romanos y $\sin$ restos visibles no sean villae, sino asentamientos dependientes de estas; pero los pocos datos disponibles y la falta de paralelos sobre otras formas de poblamiento en el medio rural de la Cataluna romana dificultan su análisis.

${ }^{8}$ Puede pensarse, por ejemplo, en ciertas prácticas como el arrendamiento de pequeñas unidades de una explotación de grandes dimensiones. Ello nos remite a la relación entre comercialización de la producción agrícola, formas de propiedad y tipos de gestión; más concretamente, permite plantear la posibilidad de vincular la pequeña explotación con el mercado a través de una relación con la gran propiedad; Cf. M. CORBIER, 1981, 26 
hasta la especialización en actividades determinadas y parciales no incluidas en la villa. Todo ello puede comportar grados distintos de autonomía de la producción. Otra cuestión, de difícil respuesta, es si esta jerarquía y descentralización/especialización de actividades supone también una autonomía de la gestión de estos núcleos (ya que no probablemente, con respecto a su propiedad $)^{8}$.

De todo lo expuesto, puede deducirse un modelo de ocupación y explotación agrícola claramente jerarquizado, en el espacio y las funciones, que expresa a la vez, unas relaciones y categorías sociales?. Expresión física de esta jerarquía es la villa, entendida como residencia y centro de gestión de una explotación. En torno a ella se distribuyen las actividades económicas complementarias o subordinadas al proceso productivo, el habitat (estacional o permanente) y las infraestructuras. Esta jerarquía caracteriza el interior de toda explotación. Pero el sistema de villae produce, también, un modelo de paisaje jerarquizado a escala regional y define un cierto tipo de organización económica del territorio allí donde se difunde (Ph. LEVEAU, 1983, 924). Este paisaje se contrapone a otros no organizados de la misma manera y que puedan responder a otras formas económicas. Ello no implica que estas formas se opongan forzosamente. De hecho, las estribaciones montañosas que limitan el valle, accidentadas y de comunicación difícil, donde no encontramos villae, pueden depender de una vinculación a estas para su explotación. Esto respondería al modelo jerarquizado de habitat y explotación ya mencionado, en el que se incluirían los pequeños núcleos que reproducen los esquemas del poblamiento ibérico precedente. Evidentemente, puede pensarse en formas de economía marginales, pero el sistema de villa puede integrar actividades diversas, no exclusivamente agrícolas (pastoreo, recursos fores-

${ }^{9}$ Como residencia (de propietarios, arrendatarios, etc.) la villa refleja un orden social y unos valores culturales. Un reflejo es la vinculación de la necrópolis al habitat, a veces con epigrafía funeraria de cierta importancia; ejemplos de ello los tenemos en: Mas de la Palma (J. MALUQUER DE MOTES, 1984, 37), Mianes (M. GENERA, 1985, 139; M. MAYER, I. RODA, 1985b, 169 170); Font de Quinto (M. GENERA, J. PONS, 1990; Benifallet (CIL 11, 4070; M. MAYER, I. RODA, 1985a, 706, figs. XIVXVI), Ginestar (CIL II, 4069; ILER 4935; M. MAYER, I. RODA, 1985a, 706, figs. XVII-XVIII); Tivissa (M. MAYER, I. RODA, 1985a, 706); Vinebre (IHE 187; IHE 291; M. MAYER, I. RODA, 1985a, 707, fig. XXIII); para una nueva inscripción en Vinebre: M. GENERA, 1990a, 197; M. GENERA et al., 1991. tales). Esta diversidad puede insertarse en el marco de una explotación con gestión centralizada, especialmente cuando la producción agrícola se vincula al mercado (A. GIARDINA, 1981, 102).

Las inversiones en tecnología, visibles en varios de los asentamientos, constituye un dato evidente de esta vinculación. Las instalaciones de prensado responden a unas actividades de procesado, muy posiblemente de vino, que exceden las necesidades domésticas de los propios núcleos; como muestran los contrapesos en el Mas de Catxorro, o la prensa y la capacidad de los depósitos de L'Aumedina. Se trata de una producción claramente excedentaria que se destina al mercado y que justifica la creación de una actividad complementaria: la fabricación de los envases para su transporte. Ello explica la aparición de alfares y los diversos tipos de prácticas artesanales en las villae ${ }^{10}$. Esta coincidencia de infraestructuras y actividades en una misma explotación respondería a un modelo ideal basado en una organización del trabajo que integra el mayor número posible (o todas) las actividades relacionadas con un mismo proceso productivo, desde el cultivo hasta el envasado y expedición del producto, en el marco de una explotación agrícola.

En el interior de esta organización adquieren sentido las prescripciones de agrónomos como Varrón, cuando establecen el carácter óptimo de una propiedad lo bastante grande como para justificar la adquisición de todas las categorías de artesanos especializados ( $R R$. I.16.4; I.2.22-23). No se trata únicamente de una voluntad de autosuficiencia. Esta referencia se entiende como un deseo de racionalizar al máximo el proceso productivo, integrando de una forma ordenada, actividades y mano de obra especializada. A la vez, esta racionalización, que responde a la búsqueda del beneficio máximo, sólo puede entenderse en relación con el proceso de la comercialización (M. CORBIER, 1981, 22; D. MANACORDA,

${ }^{10}$ Para la existencia de prácticas artesanales en el ámbito de una propiedad rural: A. GRENIER, 1934, 628, V. RIGHINI, 1971; L. CAPOGROSSI COLOGNESI, 1981, 447; D. MANACORDA, 1985. Un análisis de las fuentes legales referidas a este fenómeno en: A. DI PORTO, 1984. La vinculación alfar-villae es muy frecuente en la Tarraconense, aunque no se han analizado las implicaciones económicas de esta relación, vid. J. MIRO, 1988, 12-59 M. PREVOSTI, 1981, $538 \mathrm{ss}$., aunque la autora se limita a recoger la información disponible sin ofrecer una interpretación del fenómeno artesanal en las villae. 
1985, 143). En el mismo sentido deben entenderse las especificaciones del Digesto (D. 33.7.12.1 Ulp.) al incluir, en la amplia categoría de Instrumenta de una propiedad, un conjunto de elementos que difícilmente pueden pertenecer al medio rural, como las naves (A. DI PORTO, 1984, 3339 ss.). Su mención, en un contexto que incluye recipientes y medios de transporte y almacenaje, supone el reconocimiento de una realidad económica, que gira en torno al mercado y que unifica un conjunto de actividades que normalmente separaríamos de una explotación agrícola.

Esta relación con el mercado puede establecerse en una doble forma. Primero, desarrollando una producción agrícola excedentaria (especializada en mayor o menor medida) de artículos de consumo y cierto precio. El vino es el ejemplo más claro, por su asociación a mercados con capacidad adquisitiva y de consumo masiva y a ciertos modelos ideológicos (A. TCHERNIA, 1986). Esta producción procurará integrar el mayor número posible de actividades complementarias y tecnología en el ámbito de una explotación. Ello explica el desarrollo de ciertas actividades artesanales, ya que una producción excedentaria de vino, destinada a la venta, implica la existencia de un instrumental para su transformación, almacenaje y exportación. Este instrumental, en el que ocupa un lugar destacado la producción cerámica (ánforas, dolia), puede ser fabricado en la propia villa como medio de aprovisionar sus necesidades. A la vez, una parte de la producción artesanal puede comercializarse en explotaciones vecinas con necesidades semejantes (V. REVILLA, 1993, 130 ss.).

En segundo lugar, sin ser incompatible con la primera posibilidad, la relación con el mercado puede establecerse emprendiendo actividades diversificadas, capaces de producir un beneficio elevado con inversiones mínimas y que resultan del aprovechamiento de otros recursos en la explotación. De hecho, la venta de materias primas o instrumental (relacionados con usos domésticos o económicos) a explotaciones vecinas o núcleos urbanos constituye un medio de obtener un beneficio adicional. Todo ello es claramente explicitado por Varrón al señalar la relación del fundus con las condiciones naturales del lugar (RR. I.2.2223). En este dominio caen una serie de actividades señaladas por este autor: extracción de piedra o arena, instalación de tabernae en vías próximas a la propiedad, etc. (L. CAPOGROSSI COLOGNESI, 1981, 447). Todas ellas pueden organizarse autónomamente. Su unión en el marco de la villa refleja la diversidad de intereses económicos y la mentalidad de la clase de propietarios romanos a la que Varrón representa (A. DI PORTO, 1984, 3247).

Sin duda alguna, la situación ideal descrita por Varrón corresponde a la de una gran propiedad, capaz de producir a gran escala, con un grado máximo de especialización, que sitúa en el mercado la parte mayoritaria de su producción y que puede interesarse directamente en los circuitos de distribución. Un ejemplo de ello lo tenemos en el desarrollo de la viticultura en determinadas regiones de Italia en época tardo-republicana (D. MANACORDA, 1981; D. RATHBONE, 1981). En estos casos, gestión, infraestructura y mano de obra responden a esta elección económica y suponen unas inversiones de capital que exigen, a su vez, el incremento del beneficio aumentando el excedente comercializable. Se abre así un círculo que vincula, cada vez más, la gran propiedad con el mercado y la hace especialmente sensible a la modificación de las condiciones de este y de la circulación (M. CORBIER, 1981, 23).

Pero más allá del modelo particular ofrecido por Varrón, o por los restantes agrónomos, la relación fun$d u s$-actividades productivas-comercialización puede adoptar formas muy diversas, que afectan directamente a la organización de la producción, la gestión y las dimensiones de la propiedad, y que se encuentran en otras áreas del Imperio Romano. Estas formas deben tenerse presentes al analizar el poblamiento rural del Bajo Ebro y, de modo general, la evolución del litoral de la Tarraconense. En esta zona conocemos el desarrollo de una producción vinícola importante y una exportación intensa hacia otras provincias del occidente romano e Italia entre los siglos I a.C. y I d.C. Este fenómeno es paralelo a la creación de una industria alfarera en el medio rural, industria cuya finalidad prioritaria debía ser el abastecimiento de las necesidades de envasado y transporte de la producción vinaria y que respondería, también, a las necesidades de la vida cotidiana (cerámicas comunes o materiales constructivos de todo tipo) de la propiedad en la que se asienta o de las explotaciones vecinas. Es esta relación con el habitat y la producción agrícola la que explica la presencia de artesanado en las villae, junto a prensas y depósitos de almacenaje. La unificación física de procesos y tecnología, en una escala y formas de organización diversas (según las posibilidades del propietario), refleja, así, un modelo integrado de actividades diversas en la explotación agrícola. 


\subsection{La proyección de las formas socio-políticas y jurídicas en el espacio rural.}

\subsubsection{Estructuras de la propiedad rural y propietarios.}

Las condiciones de la investigación y los datos de que disponemos sobre las estructuras agrícolas del Bajo Ebro impiden plantear de modo satisfactorio la cuestión de las formas de propiedad y gestión de la tierra. En este estudio, hemos limitado el uso del término propiedad por la dificultad de definir sus formas a partir de una realidad exclusivamente arqueológica. Por otro lado, la naturaleza misma del problema obliga a incluirlo en la evolución histórica de la zona, con especial referencia a una serie de fenómenos de carácter más amplio. En primer lugar, el propio proceso de la conquista, acompañado de migraciones y colonización oficial, con la consiguiente posibilidad de repartos de tierras (N. DUPRE, 1973,139 ss.; J.M. RODDAZ, 1986). A ello debe añadirse la urbanización, relacionada con los fenómenos anteriores y que resulta del interés directo del estado romano por organizar administrativamente el territorio (Ph. LEVEAU, 1983, 924). La combinación de estos factores, basta pensar en el impulso que reciben las provincias hispanas bajo César y especialmente Augusto, determina las formas y resultados de la romanización en una zona concreta, el Ebro en nuestro caso. De un modo más particular, estos hechos condicionan su evolución económica y su integración en un marco provincial más amplio.

La arqueología muestra la existencia de un habitat y de unas infraestructuras y una organización de la producción vinculadas a la creación de un excedente y su comercialización, pero no nos dice nada sobre las dimensiones y formas de la propiedad. Para utilizar palabras de Leveau, la villa ne définit pas la proprieté $(1983,927)$. Los restos de villae también muestran programas arquitectónicos, técnicos y ornamentales, a veces muy elaborados. Pero ¿cómo se relacionan éstos con las dimensiones de la propiedad o las formas de gestión? Paralelamente, la inexistencia de referencias en las fuentes clásicas a propiedad y propietarios en la zona impide abordar el conjunto de relaciones jurídicas y sociales que aparecen tras las formas de concentración, apropiación o reparto de la riqueza en este medio rural y quienes son sus protagonistas. No estamos en condiciones de precisar, tan siquiera, el significado exacto de fenómenos tales como la concentración de medios de producción en ciertos núcleos y su distribución sobre el territorio. En estas condiciones, debemos limitarnos a plantear ciertas cuestiones de forma indirecta.

La primera de ellas concierne a la jerarquía de los propios asentamientos y a su función de centro de producción y gestión. A este respecto, es indudable que no todas las explotaciones debían ser capaces de realizar las inversiones en tecnología y mano de obra requeridas para la producción y expedición de un excedente y para organizarse según un modelo integrado de actividades complementarias. Una instalación de prensado o un depósito de fermentación pueden aparecer en muchos de estos lugares. Pero debían ser pocos los lugares que precisaran de tres contrapesos, y aún menos aquellos dotadas de instalaciones de prensado y alfares. La presencia de estos elementos introduce un principio de jerarquización entre los núcleos de una zona, puesto que nos indica la existencia de mayores recursos, la superior capacidad productora de una explotación y una mejor integración de ésta con el mercado. A la vez, la disponibilidad de tales infraestructuras asegura a un núcleo una posición especial que resulta de su propia autonomía para proveerse de instrumenta al tiempo que abastece al área cincundante. Quizá pudiera irse más lejos y señalar la posibilidad de que estas explotaciones centralicen el envasado y actividades relacionadas con la expedición del producto de propiedades diversas, como se ha sugerido para la Bética (J. REMESAL, 1980).

La misma selección del emplazamiento respondería a esta organización: en el centro de una amplia zona agrícola, bien comunicada con el Ebro, en el caso de L'Aumedina; junto al mismo río, en un lugar de paso necesario, en el del Mas del Catxorro. Puede pensarse, así, en un modelo de jerarquización para las villae, en un territorio dado, que responde tanto a formas concretas de organización de la producción como a las diferencias de riqueza entre los propietarios rurales. A la vez, ello puede indicar un primer paso en un proceso de concentración de la propiedad, progresivamente centralizada alrededor de núcleos más importantes en detrimento de otros cercanos. Estas posibilidades pueden aplicarse a las diversas realidades evidenciadas por la arqueologia; por ejemplo, a la jerarquización interna ya señalada que parecen presentar algunas de estas explotaciones (por ejemplo, Les Sebiques); o a los pequeños núcleos situados en las proximidades de villae, dedicados a funciones concretas del ciclo agrícola y ocupados estacionalmente. Algunos de estos pueden ser, precisamente, núcleos absorbidos por otros como resultado de transformaciones en la propiedad. 
El problema fundamental sigue siendo, sin embargo, la traducción social y jurídica de este fenómeno arqueológico. ¿Podemos hablar también de jerarquías en el interior de una clase de propietarios? Es obvio que el conjunto de propietarios rurales no constituye un grupo homogéneo, ni por su origen y posición social ni por sus posibilidades económicas. En su interior, algunos individuos con superior capacidad económica estarían en condiciones de organizar una explotación en una forma integrada, siguiendo el ideal descrito por los agrónomos y obtener, así, una mayor rentabilidad por la vinculación de sus intereses agrícolas al mercado". Al mismo tiempo, la posición social y económica de este grupo le aseguraría unas mejores posibilidades de comercializar su producción agrícola (A. TCHERNIA, 1989, 534 s.; A. DI PORTO, 1984, 3241 s.; H. PAVIS D'ESCURAC, 1977; J.H. D'ARMS, 1980; id., 1981, 48 ss.). En este contexto puede entenderse la presencia de nombres de senadores y miembros de la élite augustea, como $\mathrm{Cn}$. Lentulus Augur, sobre ánforas de la Tarraconense. Paralelamente, también debieron existir otras categorías de propiedad relacionadas con sistemas de producción más modestos. En ellas podemos incluir la pequeña propiedad campesina autosuficiente, ajena a los circuitos de comercialización; o las propiedades de tamaño medio, capaces de producir un excedente, pero que no dispondrían de los medios para realizar todo el proceso de transformación y exportación, lo que supondría algún tipo de relación con grandes explotaciones (adquisición de los envases de transporte o venta de su producción).

Las posibilidades de identificar el origen y formas de la propiedad rural dependen, en gran medida, de los datos sobre procedencia y composición social de los grupos humanos afectados. En el caso del

\footnotetext{
"La existencia de grandes propietarios en la Tarraconense, asociada a la producción vinaria, es bien conocida en época de Augusto (P. GIANFROTTA, 1982). Estos intereses agrícolas y, seguramente, comerciales, se asocian a miembros de los grupos dirigentes romanos, partidarios de Augusto. En este ejemplo, además, se aprecia uno de los factores que conducen a la redistribución y transformación de la propiedad en las provincias: la violencia política (C. NICOLET, 1988, I94); pero la época de Augusto es también de intensa colonización en Italia y las provincias occidentales, con otros tipos de propiedad, no necesariamente de gran tamaño; $\mathrm{cf}$. L. KEPPIE, 1983, 122ss., GORGES $(1979,104)$ considera que el desarrollo de la viticultura en el litoral NE de la Tarraconense se relaciona con propiétés, sans doute multiples, dont la taille générale dépasse largement la petite ou la moyenne exploitation.
}

Bajo Ebro, estos datos se limitan a algunos nombres presentes en la epigrafía rural y, especialmente, a los que aparecen sellados sobre las ánforas fabricadas localmente. Este es el caso de Sextus Domitius (en L'Aumedina) o Cn. Mussidius Nepos (en el Mas del Catxorro). La presencia de estos personajes, simultánea a la de otros nombres, sobre las primeras ánforas producidas en la Tarraconense, debe enmarcarse en un fenómeno más amplio: la emigración itálica hacia la península Ibérica en los siglos II y I a.C., que se localiza especialmente en las áreas litorales y en los valles del Ebro y Guadalquivir (E. GABBA, 1973, 289 ss.; A.J.N. WILSON, 1966; P.A. BRUNT, 1971, 234 ss.). La importancia de esta emigración reside, no sólo en su entidad cuantitativa, sino también en su condición social y económica. Se trata de grupos organizados, que reproducen en territorio provincial el conjunto de relaciones socio-jurídicas, culturales y económicas de sus comunidades de origen (cf. Caes. BC. I.51). Su asentamiento debió contribuir a la reorganización del territorio y su explotación sobre nuevas bases, complementando o anticipando la colonización oficial (A. TCHERNIA, 1989, 532 s.).

La presencia de estos nombres sobre las ánforas de la Tarraconense, sin olvidar al elemento indígena romanizado, obliga a plantear su posición en la organización del proceso productivo y su relación con la propiedad de las infraestructuras y la tierra. Dentro de la diversidad de casos posible, la relación constante villae-alfar en la Tarraconense sugiere una simultaneidad de propietario en la mayoría de los casos (dejando de lado el problema de una gestión directa o no del alfar). En esta situación, reflejada en los agrónomos y en la legislación, el taller abastece prioritariamente las necesidades de una explotación (cf. D. 8.3.5 Ulp.; 8.3.6 Paulus; 33.7.25.1 Iav.). Puede pensarse, por ello, que las marcas remiten al propietario de ambos y del vino envasado. Al mismo tiempo, un alfar puede producir envases para propiedades vecinas que no están en condiciones de fabricar sus propios recipientes. Estas posibilidades deben relacionarse con la posición social y económica del conjunto de propietarios rurales. Algunos nombres importantes asociados a la producción vinaria en la Tarraconense (por ejemplo, $\mathrm{Cn}$. Cornelius Lentulus Augur) se comprenden mejor en relación con un modelo de gran propiedad que integra agricultura y actividades complementarias; entre ellas, la producción cerámica. Puede pensarse, incluso, en una vinculación con la comercialización del producto. 
Otros individuos con nombre doble o tria nomina, muy frecuentes en los recipientes de época augustea, podrían reproducir este esquema integrador a escala más modesta: propietario de alfar y fundus, pero también podrían ser productores o propietarios de vino (ambos aspectos pueden no coincidir) que adquieren envases. Ello explicaría la pluralidad de marcas y formas de representación en los talleres. Todas estas posibilidades podrían aplicarse a los nombres identificados en el Bajo Ebro. Es indudable que la situación es muy compleja y que no estamos en condiciones de proponer soluciones globales para toda la Tarraconense (J. MIRO, 1988, 226 ss.).

\subsubsection{La ciudad y la organización de su territorio.}

La estructura de la propiedad y la condición social de los propietarios nos lleva a una cuestión próxima: la relación campo-ciudad como expresión de unas relaciones socio-económicas. Plantear el problema de la propiedad, las formas de gestión o la comercialización de la producción, obliga a plantear, simultáneamente, la situación de la ciudad en este proceso. Esta situación no es sino el resultado de su papel organizador del territorio y de su hegemonía política y social sobre el medio rural; en buena parte, como resultado de la residencia de un grupo de propietarios, que actúa, a la vez, como clase dirigente municipal (Ph. LEVEAU, 1983, 925). Sin duda, Dertosa, único núcleo urbano del curso inferior del Ebro tiene que haber jugado un papel importante. Desgraciadamente, de la ciudad romana se conoce muy poco: algunos elementos monumentales recuperados el siglo pasado; la situación de algunas necrópolis y construcciones aisladas, gracias a excavaciones recientes. A partir de estos datos puede restituirse un núcleo modesto, reducido a algunas hectáreas, del que no conocemos ni urbanismo ni edilicia pública (M. GENERA, 1985, 140 ss.; M. GENERA, J.V.M. ALBELOA, 1987).

Los escasos datos históricos y epigráficos ofrecen elementos de mayor interés. La ciudad, posiblemente constituida sobre un asentamiento indígena, se convierte en municipio en la segunda mitad del siglo I a.C.; sin duda dentro de un proceso más general de promoción jurídica de los núcleos ibero-romanos del valle del Ebro y de creación de nuevos centros, que refleja la profunda romanización de esta área $(\mathrm{H}$. GALSTERER, 1971, 31). Esta promoción se refleja en época imperial en las inscripciones públicas y privadas. A través de estas conocemos la existencia de un ordo y de un cursus municipal con magistraturas bien definidas, que reproducen los modelos de administración local romanos. En relación con estos modelos, es evidente que Dertosa tuvo que actuar como centro político-administrativo de un territorio y que sus élites dirigentes tuvieron un papel central como grupo sobre el que recae el ejercicio de la administración. Por otro lado, la importancia de este núcleo deriva de su misma posición, combinando el control del Ebro y la vinculación a la red viaria. Esta situación política y física central contribuye a explicar el dominio económico del curso inferior del Ebro. En primer lugar, por el control del tráfico fluvial y comercial, en el cual se centraliza la circulación de bienes a través del territorio. Algunos testimonios epigráficos (CIL II 4063 y 4065) e históricos (Suet. Galb. 10.4) muestran la existencia de este tráfico. Pero Dertosa también es la residencia de una clase de propietarios, identificada con la élite dirigente municipal, que proyecta su influencia sobre el territorio en una doble forma: la económica, como propietaria rural; y la político-social como grupo dirigente.

Algunos elementos muestran esta integración entre status socio-económico, poblamiento y explotación del territorio. En primer lugar, las propias características del habitat en villae, concebidas como núcleos residenciales y en las que es evidente la presencia de modelos sociales e ideológicos. Por otro lado, la misma distribución de la epigrafía en el área rural próxima a Dertosa, en relación con estas villae, muestra la aparición de personajes importantes, vinculados a la vida urbana o que disfrutan de honores municipales. Este es el caso de Iulius Lupus, Sevir Augustal, posiblemente en Dertosa, y que aparece en Font de Quinto (M. GENERA, J. PONS, 1990); o de C. Porcius Seranus, a quien se dedica una inscripción en Mianes. En este segundo caso nos encontramos ante un miembro de una familia importante de Dertosa, los Porcii Serani, con un papel destacado en la vida municipal de la ciudad y de la provincia (M. GENERA, 1985, 139; M. MAYER, I. RODA, 1985b, $169 \mathrm{~s}$.). Es muy probable que la presencia de ciertos individuos y familias en estos lugares deba ponerse en relación con propiedades cercanas.

Evidentemente, este fenómeno es mucho más complejo. Tan sólo disponemos de indicios acerca de las formas de explotación agrícola, no de la propiedad, y es difícil aplicarlos a la realidad arqueológica. Una serie de hechos se nos escapan: ¿se trataría siempre de propietarios absentistas, residentes en la ciudad y que explotarían sus tierras mediante diversas formas de 
gestión (arriendo)? ¿existe una propiedad media o pequeña, con propietarios que residen y gestionan directamente su explotación?

Un problema añadido es el de la cronología del proceso. El desarrollo de la viticultura en el Bajo Ebro (si L'Aumedina y el Mas del Catxorro constituyen un ejemplo significativo de una situación económica) se limita a época augustea. Los datos arqueológicos no permiten establecer sus orígenes o su evolución posterior. Esto nos obliga a plantear otra cuestión. Es indudable que la producción y comercialización del vino es tan sólo una de las formas o estrategias económicas desarrolladas en este medio rural y que estas formas posiblemente coexisten con otras, incluso en el ámbito de una misma explotación. Basta recordar, a este respecto, las indicaciones de los agrónomos sobre la orientación productiva del fundus, capaz de integrar actividades económicas muy diversas.

Por otro lado, la viticultura ha dejado un mayor número de testimonios materiales (prensas, alfares, el propio material anfórico) que otras actividades. Ello produce, forzosamente, una visión desequilibrada de una realidad más compleja y deja sin resolver numerosos interrogantes: la relación exacta entre un modelo de poblamiento (en villae), unos sistemas de gestión y producción y una agricultura orientada a la comercialización de un excedente; los factores sociopolíticos o económicos que han permitido el desarrollo de una producción excedentaria; el momento inicial y la duración de esta economía vitivinícola. Se trata, en suma, de establecer hasta qué punto unas estrategias económicas han constituido un modelo dominante o uno de los modelos adoptados, cómo ha actuado este modelo sobre el paisaje rural, el marco social en el que se incluye y la duración del proceso. Estas precisiones son necesarias. Difícilmente, podemos conocer la continuidad o evolución posterior del poblamiento y su marco económico, en los s. I y II d.C. o en el Bajo Imperio, cuando apenas se han planteado los términos del debate y las líneas de investigación a seguir para un período mejor documentado arqueológicamente, como es la época augustea. Esta situación se advierte, igualmente, al intentar un análisis del poblamiento rural en otras áreas de la Tarraconense donde la viticultura conoció un desarrollo importante: Maresme, Baix Llobregat, Vallès (M. PREVOSTI, 1981, 555 ss.; A. TCHERNIA, 1986, 271 s.).
Los mismos problemas se plantean al analizar la continuidad de las villae en la zona. En los casos mejor conocidos (Casa Blanca, Berrugat, Mas del Catxorro) el habitat se prolonga hasta los s. V y VI d.C. Todos los lugares muestran la presencia de importaciones africanas y orientales en el Bajo Imperio, lo que indica la pervivencia del Ebro como gran vía de comunicación. Además, la perduración no se limita a grandes asentamientos. Continúan ocupados pequeños núcleos como Mianes II, por ejemplo. Sin embargo, la falta de excavaciones dificulta conocer el grado de continuidad del poblamiento, su entidad (arquitectura, infraestructuras) y, especialmente, las bases económicas en que se fundamenta su estructuración: tipos de agricultura, sistemas de producción y gestión, propiedad, organización de la mano de obra. La definición de nuevas formas de paisaje rural, en las que se integraría este poblamiento, depende de un mejor conocimiento de las transformaciones económicas y sociales producidas e la Antiguedad Tardía.

\section{BIBLIOGRAFÍA}

ABRIL I GUANYABENS, J., 1931: Un capitol de la meva actuació a Tortosa, Tortosa.

AMOURETTI, M.C. et al., 1984: «A propos du pressoir à huile: de l'archéologie industriellè à l'histoire», MEFRA, 96-1, 379-421.

ALBELOA, J.V. M.H ${ }^{\mathrm{a}}$, 1990: «Vil-la de Casa Blanca, Jesús-Tortosa (Baix Ebre). Campanya 1986», Butlletí Arqueològic, época V, 12, 216-218.

BALIL, A., RIPOLL, E., 1952: «Actividad arqueológica en Cataluña durante los años 1950 y 1951 », $A E A, 25,178-186$.

BAYERRI, E. 1948: Historia de Tortosa, vol. V, Tortosa.

BELTRÁN, A., 1961: «El río Ebro en la antigüedad clásica», Caesaraugusta, 17-18, 65-79.

BRUN, J.P., 1986: L'oleiculture antique en Provence. Les huileries du département du Var, RAN Suppl. 15, París.

BRUNT, P.A., 1971: Italian Manpower 225 B.C.-A.D. 14, Oxford,

CABRE, D., 1974: Riba-Roja d'Ebre i el seu terme municipal, Tarragona.

CAPOGROSSI COLOGNESI, L., 1981: «Proprietà agraria e lavoro subordinato nei giuristi e negli agronomi latini tra Repubblica. e Principato» en A. GIARDINA-A. SCHIAVONE (eds.), Società romana e produzione schiavistica, 1, 445-454.

CARRERAS CANDI, F., 1940: La navegación en el río Ebro. Notas históricas, Barcelona.

CLAVEL-LEVEQUE, M., 1984: «Cadastres, developpement et viticulture a l'èpoque romaine: terroirs du Biterrois», $57 e$ Congrés Fed. Hist. du Languedoc Mediterranéen et du Roussillon, Beziers 1984, Montpellier.

CORBIER, M., 1981: «Proprietà e gestione della terra: grande proprietà fondiaria ed economia contadina», en A. GIARDINA-A. SCHIAVONE (eds.), The Seaborne Commerce of Ancient Rome: Studies in Archaeology and History. MAAR XXXV (1980) 77-89. 
-Id., 1981: Commerce and Social Standing in Ancient Rome, Harvard.

DUPRE, N., 1973: «La place de la vallée de l'Ebre dans l'Espagne romaine», $M C V, 9,133-175$.

—Ead., 1983: «La vallée de l'Ebre et les routes transpyréneenes antiques», Les voies anciennes en Gaule et dans le monde romain occidental, Caesarodunum XVIII, 393410.

—Ead., 1985a: «Les villes ibero-romaines de la vallée de l'Ebre du IIe s. avant J.C. au milieu du I s. apres J.C.», Les debuts de l'urbanisation en Gaule et dans les provinces voisines. Caesarodunum XX, 281-291.

—Ead., 1985b: «La forêt antique dans la région de l'Ebre», Le bois et la forêt en Gaule et dans les provinces voisines, Caesarodunum XXI, 274-284.

-Ead., 1989: «Front, frontière, frontieres dans le nord-est de l'Espagne romaine», Fronteras, 3.er Coloquio Internacional Arqueologia Espacial, Teruel, 173-187.

—Ead., 1990: «Vigne et vin dans la region de l'Ebre antique», Archéologie de la vigne et du vin. Caesarodunum XXIV 123-141.

ESTEVE GALVEZ, F., 1955: «Investigaciones arqueológicas en las terrazas cuaternarias del curso inferior del Ebro. Itinerario primero: de Amposta a la Carrova y Camp Redó», NAH, 3-4.

GABBA, E., 1973: Esercito e società nella Repubblica romana, Firenze.

GALSTERER, H., 1971: Untersuchungen zum römischen Städtewesen auf der ibersichen Halbinsel, Berlín.

GENERA, M., 1977: «Aportaciones a la arqueología de la Ribera del Ebro», Cuad. Prehist. Arqueol. Castellonenses, 4, 281285.

—Ead., 1982: «Inventari arqueològic de la Ribera d'Ebre», Fonaments, 3, 47.-134.

-Ead., 1983-84: «El jaciment de Barrugat: noves dades per al coneixement de la Tortosa d'epoca romana», Pyrenae 19-20, 287-288

—Ead., 1985: «Estat actual de la recerca sobre la Dertosa romana», Quaderns d'historia tarraconense, V.

—Ead., 1990a: «Les últimes descobertes en el Pas de l'Ase», $8^{\circ}$ Col-loqui Internacional d'Arqueologia, Puigcerda 1988, $197-$ 201.

-Ead., 1990b: «La Fontjoana, Vinebre (R. d'Ebre). Campanya: 1988», Butlletí Arqueològic, época V, 12, 211-213.

—Ead., 1990c: «Barrugat, Bitem-Tortosa (Baix Ebre)», ibid., 194195.

GENERA, M., JASSANS, M.J., 1978: «Nuevas aportaciones a la arqueología de la Ribera d'Ebre», Cuad. Prehist. Arqueol. Castellonenses, 5, 293-303.

GENERA, M., ARBELOA, J.V.M.a, 1987: «Estat actual de la investigació arqueologica sobre la Dertosa romana i la seva area d'influència», Tribuna d'Arqueologia 1986-87, Barcelona.

GENERA, M., PONS, J., 1990: «Noves dades sobre la Dertosa romana: una troballa recent a Camp-Redó», $8^{e}$ Col-loqui Intemacional d'Arqueologia, Puigcerda 1988, 215-219.

GENERA, M. et al., 1991: «Un vestigi del mon romà a la Ribera: l'estela de Vinebre», Tribuna d'arqueologia 1989-90, Barcelona, 135-145.

GIANFROTTA, P., 1982: «Lentulo Augure e le anfore laietane», Tituli, 4, 475-479.

GIARDINA, A., 1981: «Allevamento e economia della selva in Italia meridionale», en A. GIARDINA-A. SCHIAVONE (eds.), I, 87-113.

GORGES, J.G., 1979: Les villas hispano-romaines. Inventaire et problematique archeologique, París.
GRENIER, A., 1934: Manuel d'archélogie gallo-romaine, vol. VI.2; 1960: vol. IV.

IZQUIERDO, P., 1993: «Un nou centre productor d'àmfores al Baix Ebre: el Mas del Catxorro de Benifallet», Homenatge al Prof. Miquel Tarradell (Barcelona).

KEPPIE, L., 1983: Colonisation and Veteran Settlement in Italy 47-14 BC, Roma.

LAFON, X., 1981a: «A propos des villas de la zone de Sperlonga. Les origines et le dévelopement de la villa maritima sur le littoral tyrrhénien a l'epoque républicaine», MEFRA, 93-1, 297353.

—Id., 1981b: «A propos des vilae républicaines. Quelques notes sur les programmes décoratifs et les commanditaires», L'art décoratif à Rome a la fin de la République et au debut du Principat, Roma 1979, 151-172.

LEVEAU, Ph., 1983: «La villa antique et l'organisation de l'espace rural: villa, ville, village», Annales ESC, 38-4, 920-942.

MALUQUER DE MONTES, J., 1984: La necrópolis paleoibérica de «Mas de Mussols», Tortosa, Tarragona, Barcelona.

MANACORDA, D., 1981: «Produzione agricola, produzione ceramica e propietari nell'Ager Cosanus nel I a.C.», en A. GIARDINA-A. SCIAVONE (eds.), II, 3-54.

-Id., 1985: «Schiavo manager e anfore romane: a proposito dei rapporti tra archeologia e storia del diritto», Opus, IV, 141-151.

MAYER, M., RODA, I., 1985a: «Consideraciones sobre el conjunto epigráfico de Dertosa», XVII CNA, Logroño, 1983, Zaragoza, 701-737.

MAYER, M., RODA, I., 1985b: «L'epigrafia romana a Catalunya, estat de la quiestió i darreres novetats», Fonaments, 5, 161-186.

MIRÓ, J., 1988: La producción de ánforas romanas en Catalunya. Un estudio sobre el comercio del vino de la Tarraconense (s. I a. C. -I d. C.), Oxford.

MOROTE BARBERA, J.G., 1979: «El trazado de la Via Augusta desde Tarracone a Carthagine Spartaria. Una aproximación a su estudio», Saguntum, 14 139-164.

NICOLET, Cl., 1988: Rendre à César: économie, societé, fiscalité dans la Rome antique, Parîs.

NOLLA, J.M. ${ }^{a}$, PADRÓ, J., SANMARTI, E., 1980: «Exploració preliminar del forn d'àmfores de Tivissa (Ribera d'Ebre)», Cypsela, III, 193-218.

PALLI, F., (1985): La vía Augusta en Cataluña, Barcelona.

PAVIS D'ESCURAC, H., 1977: «Aristocratie sénatoriale et profits commerciaux», Ktema, 2, 339-355.

DI PORTO, A., 1983: «Impresa agricola ed attività collegate nell'economia della villa. Alcune tendenze organizzative», Sodalitats. Scritti in onore di A. Guarino, Napoli, vol. VII, 3235-3277.

PREVOSTI, M., 1981: Cronologia i poblament a l'àrea rural d'lluro, Mataró.

PUCH, E., 1986-87: «Poblamiento ibérico en la mitad meridional de la Terra Alta (Arnès, Bot y Horta de Sant Joan)», Butlletí Arqueologic, época V, 12, 15-33.

RATHBONE, D., 1981: «The Development of the Agriculture in the Ager Cosanus during the Roman Republic: Problems of Evidence and Interpretation», JRS, 71, 10-23.

REMESAL, J., 1980: «Reflejos económicos y sociales en la producción de ánforas olearias béticas», Producción y comercio del aceite en la antigüedad, I Congreso Internacional, Madrid 1978, 131-153.

REMESAL, J., REVILLA, V., 1991: «Weinamphoren aus Hispania Citerior und Gallia Narbonensis in Deutschland und Holland», $F W B, 16,389-439$ 
REVILLA, V., 1993: Producción cerámica y economía rural en el Bajo Ebro en época romana. El alfar de L'aumedina (Tivissa, Tarragona), Barcelona.

RIGHINI, V., 1971: «Officine artigianali e nuclei industriali nella villa romana», La villa romana, Giornata di Studi Russi, Faenza 1970, Faenza, 29-36.

RODDAZ, J.M., 1986: «Guerres civiles et romanisation dans la vallèe de l'Ebre», Hommage à Robert Etienne, REL, 88, 317-338.

ROSSITER, J.J., 1981: Wine and Oil Processing at Roman Farms in Italy», Phoenix, 35-4, 345-361.

TCHERNIA, A., 1979: «L'atelier d'amphores de Tivissa et la marque Sex. Domiti», Mélanges Jacques Heurgon, Roma 1976, 973-979.

-Id., 1986: Le vin de l'ltalie romaine, Roma
-Id., 1989: «Encore sur les modéles économiques et des amphores», Amphores romaines et histoire economique, dix ans de recherche, Siena 1986, Roma, 529-536.

TOSI, G., 1989: «Considerazioni sull'interdependenza tra villa e agro centuriato», Misurare la terra: centuriazioni e coloni nel mondo romano. II caso Veneto, Modena, 85-92

VALLAT, J.P., 1983: «Architecture rurale en Campanie Septentrionale du IV.e s. av. J.C. au ler ap. J.C.», Architecture et societé. De l'archaïsme grec à la fin de la République romaine, Roma 1980, 247-267

WHITE, K.D., 1970: Roman Farming London.

-Id., 1975: Farm Equipment of the Roman World, Cambridge.

WILSON, A.J.N., 1966: Emigration from Italy in the Republican Age of Rome, New York. 